\title{
CONFORMATIONAL STUDIES OF PER-O-TRIMETHYLSILYL DERIVATIVES OF D-FRUCTOSES AND OLIGOSACCHARIDES CONTAINING $\beta$-D-FRUCTOFURANOSE RESIDUES BY 220- AND 300-MHz P.M R SPECTROSCOPY
}

Dirk G Streefkerk, Marius J A de Bie, and Johannes $F$ G Vliegenthart Laboratory of Organtc Chemistry, Croesestraat 79, Umversity of Utrecht, Utrecht (The Netherlands)

(Received October 11th, 1973, accepted for publication November 19th, 1973)

\section{ABSTRACT}

The interpretation of $220-$ and $300-\mathrm{MHz} \mathrm{p} \mathrm{m} \mathrm{r}$ spectra and the accurate chemical shifts and coupling constants of a number of per- $O$-trimethylsılyl-(TMS-) $D$-fructose derivatives and TMS-oligosaccharides containing $\beta$-D-fructofuranose residues are presented On the basis of calculations with an adapted Karplus equation, it is concluded that TMS- $\alpha$ - and $-\beta$-D-fructopyranose occur in the ${ }^{2} C_{5}(\mathrm{D})$ chair conformation, whereas the D-glucopyranose rings in the oligosaccharides adopt the usual ${ }^{4} C_{1}(\mathrm{D})$ chair conformation The structure of the latter units is very similar to that of TMS- $\alpha$-D-glucopyranose The ${ }^{4} E$ (D) envelope and ${ }^{4} T_{5}(D)$ twist are the principal conformations of the $D$-fructofuranose rings The conformation of the furanose ring depends on the number and kind of monosaccharide units attached thereto The calculated, preferred conformation of the C-5- $\mathrm{CH}_{2} \mathrm{OTMS}$ group of the D-fructofuranose moieties correlates with the time-averaged displacement of $\mathrm{C}-4$ above the plane of $\mathrm{C}-2, \mathrm{C}-3$, and $\mathrm{O}-5$.

\section{INTRODUCTION}

Previously, we reported on the determination, by means of high-resolution $\mathrm{p} m \mathrm{r}$. spectroscopy, of the conformation of the pyranord rings and of structural details of TMS-aldohexoses ${ }^{1,2}$, TMS-aldohexosyl disacchandes ${ }^{1}$, and TMS-6deoxyaldohexoses ${ }^{2}$. We have also studied compounds containing furanold rings, particularly TMS derivatives of the various anomeric forms of D-fructose and of some oligosaccharides containing D-fructose. The latter types of compound occur frequently in plant material and are under investigation in our laboratory ${ }^{3}$ Comparison of the oligosacchandes permits a study of the conformation of the furanord ning in relation to the number and type of monosaccharide moretres attached thereto.

For the determination of the conformation of furanond rings in solution, account must be taken of the low energy barners between the different conformations, which result in rapid interconversion ${ }^{4}$. The structure of the furanord ring has been estimated $^{4-6}$ by several approaches in which a set of closely related conformations is 
used to describe the actual situation This set of conformations is usually deduced from comparisons of the dihedral angles between the vicinal ring protons, as calculated from the observed coupling constants and the angles obtained from models of the 20 ideal conformations [10 twist $(T)$ and 10 envelope $(E)$ conformations] In addition to the contributions of different conformations, the coupling constants may also reflect changes in the time-averaged degree of puckering of the ring ${ }^{5,6}$ For fructofuranoses (Fruf), the determination of the ring structure is complicated, because only two coupling constants $\left(J_{3,4}\right.$ and $\left.J_{4,5}\right)$ are avalable, whereas there are three for aldohexofuranoses and aldopentofuranoses

In the literature, the ${ }^{3} E(D)$ conformation has been proposed for the $\alpha$-D-Fru $f$ ring, in $1^{\prime}, 2$-anhydro-[1-( $\alpha$-D-Fruf $f-\beta$-D-Fruf] and the ${ }^{4} E$ (D) conformation for the $\beta$-D-Fruf ring in this compound ${ }^{7}$ This ring conformation is also suggested for $\beta$-D-Fruf in per- $O$-acetylsucrose ${ }^{7,8}$ and in per- $O$-acetyl derivatives of higher oligosaccharides $^{8}$

RESULTS

Interpretation of the spectra - The 220-MHz p m r spectra of the TMS derivatives of $\alpha$-D-fructopyranose (1), $\beta$-D-fructopyranose (2), $\beta$-D-fructofuranose (3), methyl $\beta$-D-fructofuranoside (4), sucrose (5), 1-kestose (6), and melezitose (7) were recorded for solutions in acetone- $d_{6}$ The spectra of 6 and 7 were also measured at $300 \mathrm{MHz}$

The spectra have the following general features The TMS-methyl groups give rise to strong, sharp singlets in the region $\delta$ 0.1-0 3 (Table $)$ The protons attached to the carbon skeleton of the sugar residues are observed between $\delta 33-45$, but the anomeric protons $(\mathrm{H}-1)$ of the D-glucopyranose residues in 5, 6, and 7 resonate in the range $\delta 50-55$, for the numbering of the protons, see Fig 1 The magnetically nonequivalent $\mathrm{C}-1$ protons of the n-fructose residues give rise to a readily detectable $\mathrm{AB}$ pattern one of the doublets is present in the region $\delta 34-36$ while the other is located between $\delta 35$ and 39

The first-order interpretation of the spectra was checked and refined by calculation of theoretical spectra, using the spin-simulation program SIMEQ ${ }^{9}$ In these calculations, the vicinal coupling constants were taken as positive and the geminal couplings as negative In an iterative, interactive procedure, the calculated spectrum was refined until a good agreement was obtaned with the observed spectrum The sub-spectra of the monosacchande units of the di- and tri-saccharides were simulated separately For the final refinements, the sub-spectra were added and plotted together. In this way, several obscured signals were traced and a moredetailed interpretation was achieved

The D-fructose monosaccharides (1-4) - The initial $\mathrm{p} m \mathrm{~m}$ parameters, which were readily obtained from a simple, first-order, sub-spectral analysis, were refined by iterative spectrum simulations in which the proton system was treated as a seven-spin system ABCDEFG $\left(\mathrm{H}-1,1^{\prime}, 3,4,5,6,6^{\prime}\right)$ 

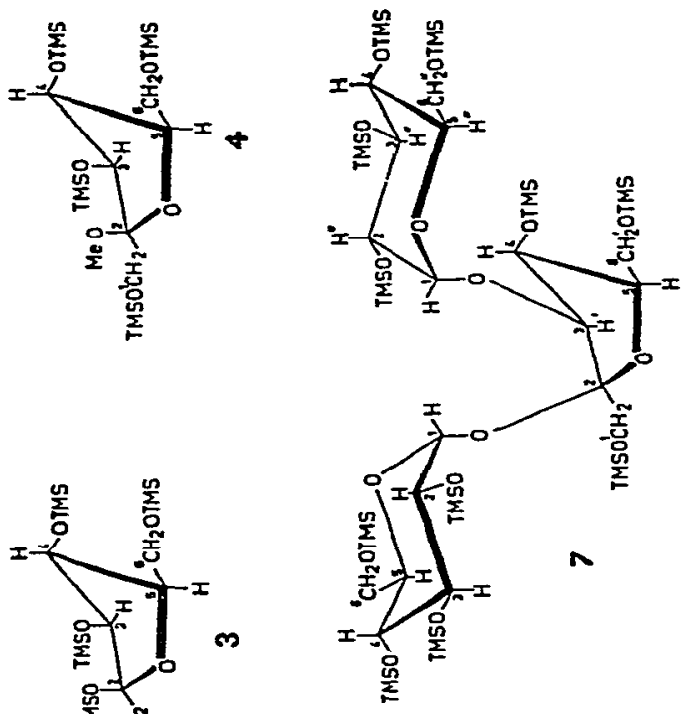

늘 등

몰

늉

$\stackrel{\mathrm{E}}{\mathrm{E}}$

气 응

点咅

空

인

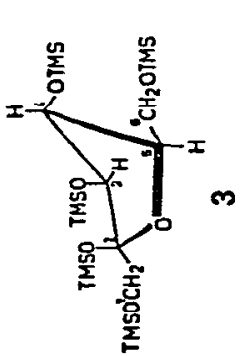

요용

든

끙 홍

돌 옹

文占

号 兽

풍

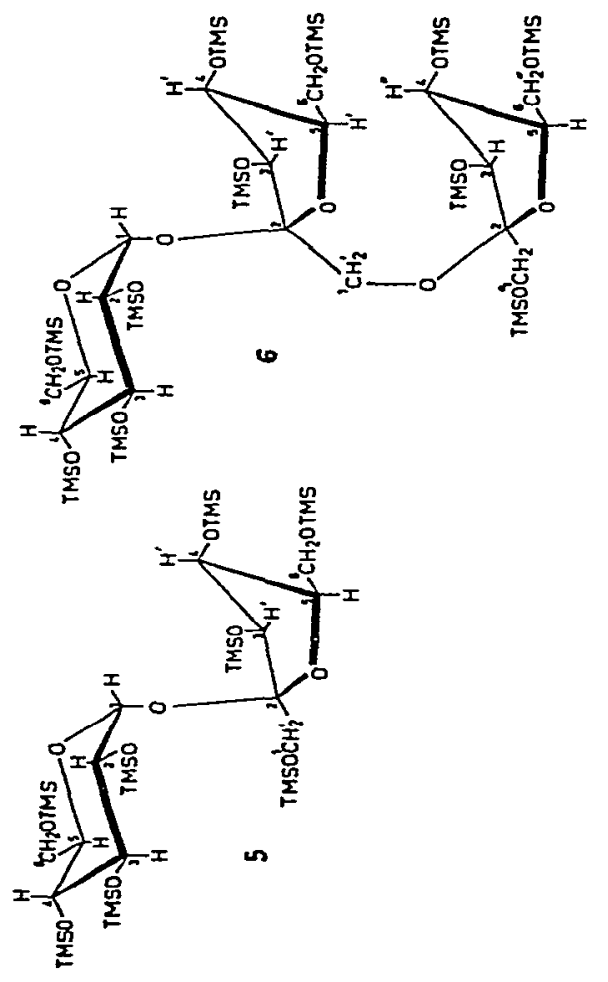

的

总是
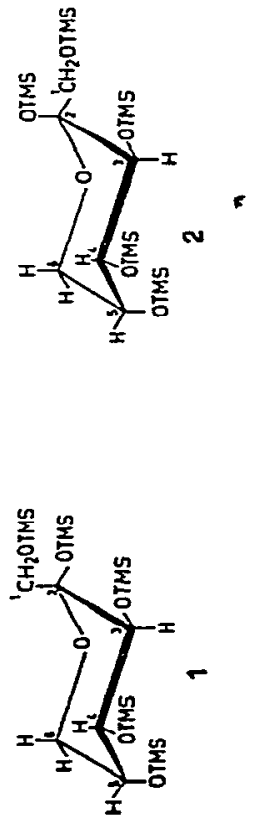

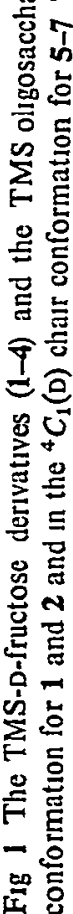




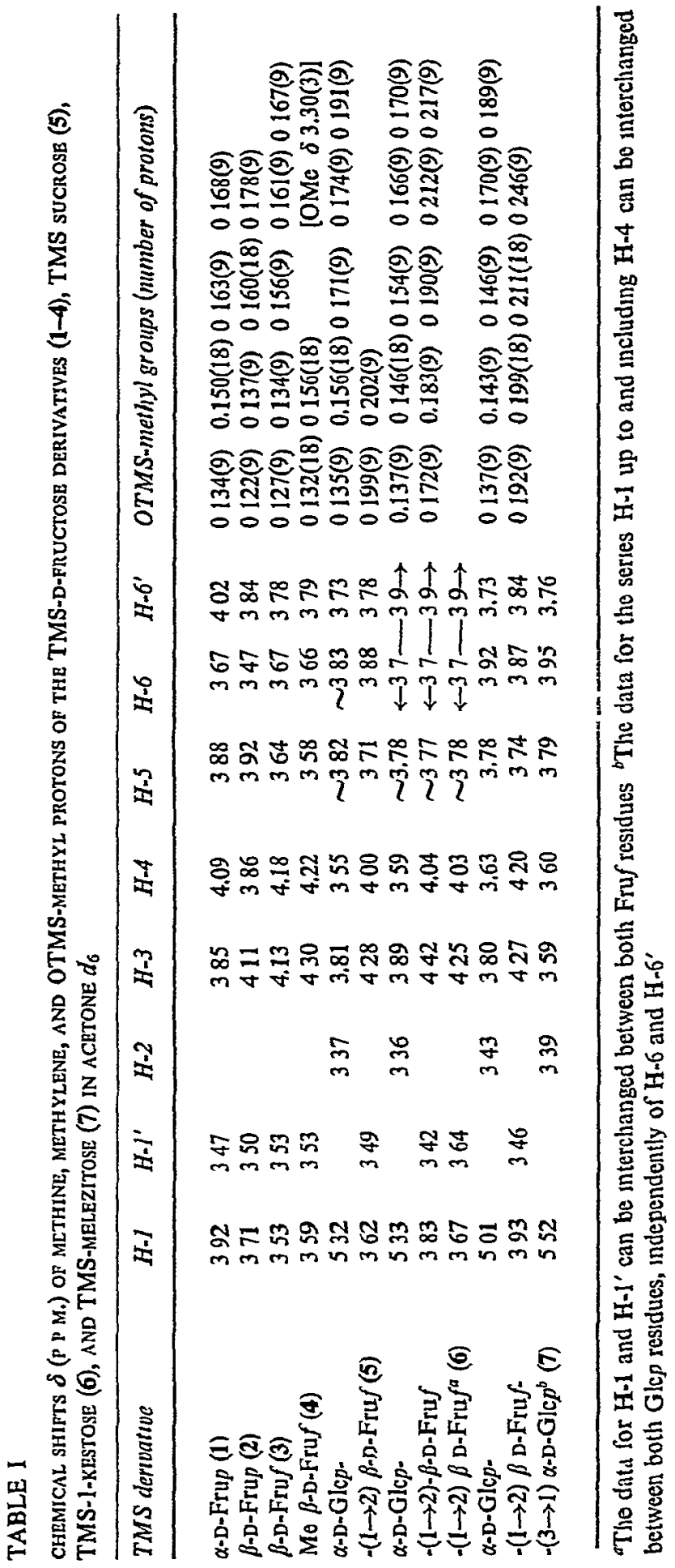


The sucrose derivative 5. - Using the spacing of the doublet of $\mathrm{H}-1$, the quartet at $\delta 337$ was assigned to $\mathrm{H}-2$ of the D-glucopyranose (Glcp) residue On the basis of the spacings, the triplet at $\delta 355$ was assigned to $H-4$. The doublet at $\delta 4.28$ and the triplet at $\delta 400$ were assigned to $H^{\prime}-3$ and $H^{\prime}-4$, respectively, of the D-fructofuranose (Fruf) residue The remaining multiplet ( $\delta 37-39$ ) consisted of the triplet of $\mathrm{H}-3$ and the signals of $H-6, H-6^{\prime}$, and $H-5$ of both units A farly good agreement between the observed and calculated spectrum was obtained when the following values were used $J_{5}{ } 24 \mathrm{~Hz}, J_{5,6}, 18 \mathrm{~Hz}$, and $J_{6,6^{\prime}}-112 \mathrm{~Hz}$ (derived from the data for TMS- $\alpha$ D-Glc $p$ and TMS- $\alpha, \alpha$-trehalose ${ }^{1}$ ) Because of the small difference in chemical shift between $\mathrm{H}-5$ and $\mathrm{H}-6, J_{5,6}$ could not be determined very accurately

The 1-kestose derivative 6 - The interpretation of the spectrum of 6 was greatly facilitated by comparison with the spectrum of 5 The signals at $\delta 533,336$, and 359 were assigned to $\mathrm{H}-1, \mathrm{H}-2$, and $\mathrm{H}-4$, respectively, of the Glcp residue The two doublets and two triplets $(\delta, 0-44)$ were attributed to $\mathrm{H}-3$ and $\mathrm{H}-4$ of the Fruf residues As will be discussed later, the assignment of these signals to $\mathbf{H}^{\prime}-3$ or $\mathbf{H}^{\prime \prime}-3$ and to $\mathrm{H}^{\prime}-4$ or $\mathrm{H}^{\prime \prime}-4$ was possible on the basis of calculated dihedral angles between $\mathrm{H}-3$, $\mathrm{H}-4$, and $\mathrm{H}-5$ of each unit $A$ specific assignment of the two $\mathrm{AB}$ patterns, arising from the $C-1$ protons of the Fruf residues, to $H^{\prime}-1$ and $H^{\prime}-1^{\prime}$ or to $H^{\prime \prime}-1$ and $H^{\prime \prime}-1^{\prime}$ was not possible The 10-proton multiplet at $\delta 37-39$ includes a triplet for $\mathrm{H}-3$ and the signals for $H-6, H-6^{\prime}$, and $H-5$ of the three monomer residues This multiplet could not be analysed further, nevertheless the positions of the $\mathrm{H}-5$ signals could be traced within $002 \mathrm{p} \mathrm{p} \mathrm{m}$ by accurate simulation of the relative intensities of the outer peaks of the triplets for $\mathrm{H}-4$ In these simulations, the proton systems were treated as ABCDE systems $\left(H-1,2,3,4\right.$, and 5 of the Glcp residue and $H-1,1^{\prime}, 3,4$, and 5 of the Fruf residues)

The melezitose derivative 7 - The doublets of the anomenc protons of the Glcp residues were centred at $\delta 552$ and 501 and the quartets of the $\mathrm{H}-2$ protons at $\delta 343$ and 339 The pattern at $\delta 36$ consisted of a quartet and a 2-proton multsplet, which were assigned to $\mathrm{H}-4$ of one Glcp residue and to $\mathrm{H}-3$ and $\mathrm{H}-4$ of the other Glcp residue, respectively This assignment was confirmed by spectrum simulation Taking a difference in chemical shift of $\mathrm{H}-3$ and $\mathrm{H}-4$ of $3 \mathrm{~Hz}$ and $J_{3,4} 90 \mathrm{~Hz}$, a correct simulation of the multiplet was obtained and the lines of the $\mathrm{H}-2$ quartet were broadened as in the observed spectrum (Fig $2 a$ and $b$ )

The two quartets at $\delta 392$ and 3.73 showed the same spacings $(25,1.8$, and $112 \mathrm{~Hz}$ ) as observed for $\mathbf{H}-6$ and $\mathbf{H}-\mathbf{6}^{\prime}$ of the Glcp residue of 5 Also, the quartets at $\delta 395$ and $376(22,20$, and $11.8 \mathrm{~Hz})$ were identufied as C-6 protons of a Glcp residue By accurate simulation of the relative intensities of these quartets, the positions of the $\mathrm{H}-\tilde{\mathbf{s}}$ signals could be determined As the signals of these protons are largely obscured, the data for $\mathrm{H}-1$ up to and including $\mathrm{H}-4$ can be interchanged between both Glcp residues independently from H-6 and H-6'

The remaining signals in the spectrum were attributed to the Fruf residue the doublets at $\delta 393$ and 3.46 to $\mathrm{H}^{\prime}-1$ and $\mathrm{H}^{\prime}-1^{\prime}$, the doublet at $\delta 427$ and the triplet at $\delta 420$ to $H^{\prime}-3$ and $H^{\prime}-4$, respectively The multuplet at $\delta 385$ was assigned to $H^{\prime}-6$ 


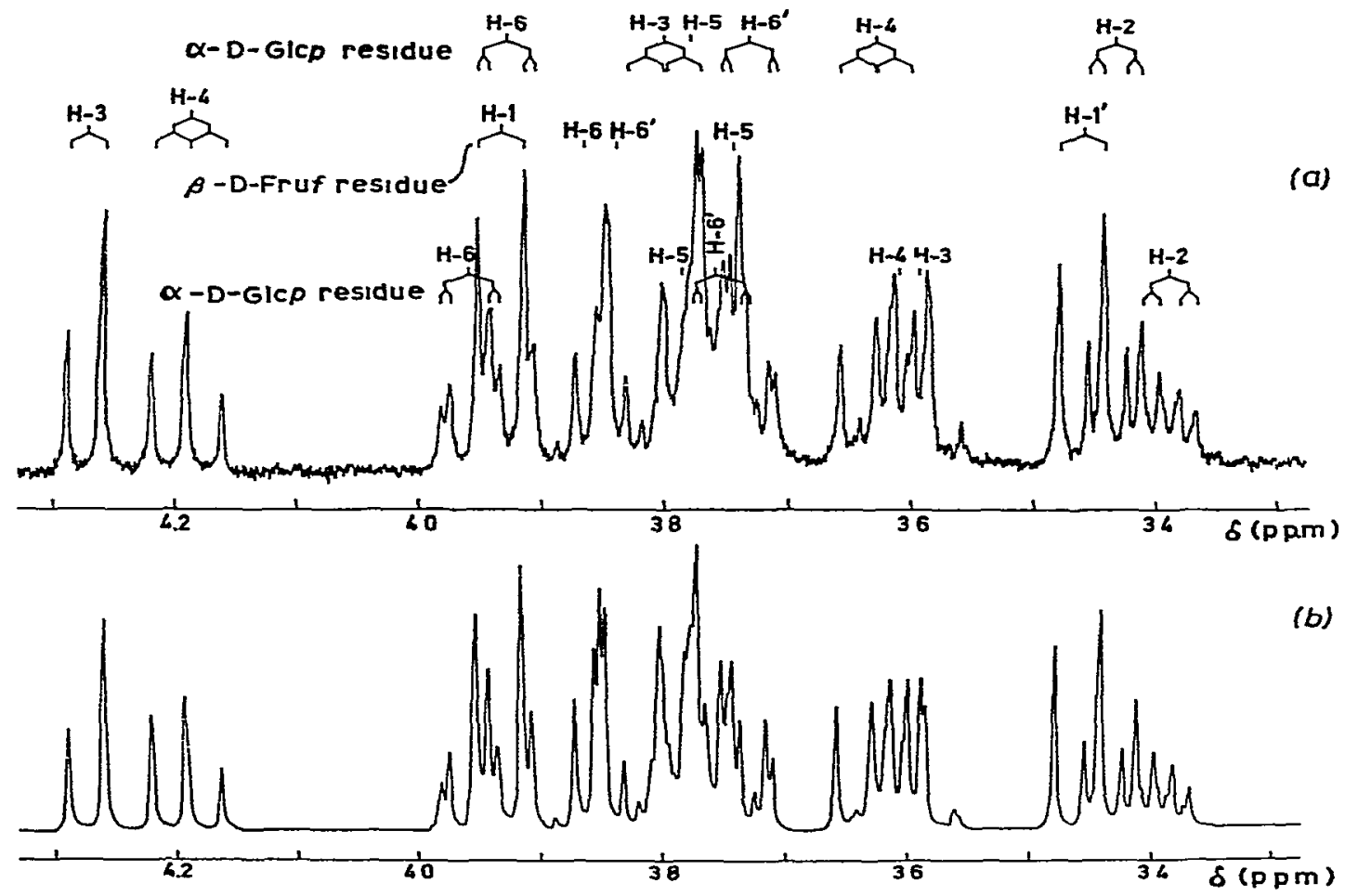

Fig 2 300-MHz p in $r$ spectrum of the non-anomenc protons of TMS-melezitose (7), $a$ observed spectrum, $b$ calculated spectrum

and $H^{\prime}-6^{\prime}$. The magnitudes of the vicinal coupling constants $J_{5,6}$ and $J_{5,6}$, were obtained by spectrum simulation, $J_{6,6}^{\prime}$, could not be determined because of the small difference in chemical shift between $H^{\prime}-6$ and $H^{\prime}-6^{\prime}$

The combination of the theoretical spectra of the three monomer units (F1g $2 b$ ) resembles closely the observed spectrum of 7 (F1g $2 a$ ) However, the complex pattern at $\delta 37-38$, which includes the three multıplets for the $\mathrm{H}-5$ protons, could not be reproduced exactly

The structure of the fructopyranose rings in 1 and 2 - The type of ring conformation in 1 and 2 was determined by comparison of the observed coupling constarts $J_{34}, J_{4,5}, J_{56}$, and $J_{56}$, with those calculated* from the dihedral angles between the

*For the calculation of coupling constants from dihedral angles and for the reversed procedure, the following, modified Karplus relation ${ }^{1}$ is used

$$
J_{\mathrm{HH}}=(6 \sigma-10 \cos \phi+56 \cos 2 \phi)\left(1-\sum_{i=1}^{4} \mathrm{f}_{1} \Delta \mathrm{X}_{1}\right)
$$

in which $\phi$ is the dihedral angle between the protons in the fragment $\mathrm{H}-\mathrm{C}-\mathrm{C}^{\prime}-\mathrm{H}^{\prime}, \Delta \mathrm{X}_{\mathrm{i}}=\mathrm{X}_{\mathrm{R}}-\mathrm{X}_{\mathrm{H}}$ represents the difference in electronegativity $X$ between a substituent $R$ and hydrogen, $f_{i}$ is 015 when the dihedral angle $\theta$ between $R$ and $H$ in $H-C-C^{\prime}-R$ is larger than $90^{\circ}$, and 005 when $\theta$ is smaller than $90^{\circ}$ The following values for $X$, as determined by the method of Cavanaugh and Dalley ${ }^{10}$, were used $X_{H} 21, X_{O_{\text {TMS }}} 35, X_{C-O} 25, X_{\mathrm{OCH}_{3}} 33, X_{O_{5}} 33$, and $X_{O_{A c}} 37$ 
vicinal ring protons in fourteen ideal conformations $[2$ chair $(C), 6$ boat $(B)$, and 6 skew-boat $(S)$ conformations] Only the coupling constants of the ${ }^{2} C_{5}(D)$ conformation correspond to the observed data In any other conformation, at least one coupling constant deviates more than $35 \mathrm{~Hz}$

The geminal coupling constants $J_{6,6}$ in 1 and 2 also support the ${ }^{2} C_{5}(\mathrm{D})$ conformation In TMS-aidohexopyranoses, $J_{6}$, varies between -95 and $-12 \mathrm{~Hz}$ When the C-5-O-5 bond is trans-coplanar with one of the geminal protons H-6 or H-6', values between -11 and $-12 \mathrm{~Hz}$ are found, while trans-coplanarity with 0-6 gives rise to values between -95 and $-10 \mathrm{~Hz}$ The $J_{6,6}$ values of 1 and $2(-11.6$ and $-118 \mathrm{~Hz}$, respectively, Table II) point to trans-coplanarity of the C-O bond of the C-5-OTMS group with one of the C-6 protons This situation is present in the ${ }^{2} C_{5}(D)$ conformation (Fig 1)

TABLE II

COUPLING CONSTANTS (Hz) OF METHINE AND METHYLENE PROTONS OF THE TMS-D-FRUCTOSE DERIVATIVES (1-4), TMS-SUCROSE (5), TMS-1-KeSTOSE (6), AND TMS-MELEZITOSE (7) FOR SOLUTIONS IN ACETONE- $d_{6}$

\begin{tabular}{|c|c|c|c|c|c|c|c|c|c|}
\hline $\begin{array}{l}\text { Cont- } \\
\text { pound }\end{array}$ & Configuration & $\mathbf{J}_{1} \mathbf{I}$ & $J_{12}$ & $J_{23}$ & $\mathbf{J}_{34}$ & $\mathbf{J}_{45}$ & $J_{56}$ & $J_{56}$ & $\mathrm{~J}_{66}$ \\
\hline 1 & $\alpha-\mathrm{D}-\mathrm{Frup}$ & -102 & & & 88 & 28 & 34 & 16 & -116 \\
\hline 2 & $\beta$-D-Frup & -105 & & & 94 & 29 & 21 & 12 & -118 \\
\hline 3 & $\beta$-D-Fru $f$ & $a$ & & & 55 & 55 & 52 & 42 & -110 \\
\hline 4 & Me $\beta$-D-Fruf & -109 & & & 75 & 75 & 44 & 32 & -112 \\
\hline 5 & $\begin{array}{l}x-\mathrm{D}-\mathrm{Gl} c p- \\
-(1 \rightarrow 2)-\beta-\mathrm{D}-\mathrm{Fruf} f\end{array}$ & -114 & 33 & 92 & $\begin{array}{l}87 \\
81\end{array}$ & $\begin{array}{ll}9 & 6 \\
8 & 1\end{array}$ & $\begin{array}{r}24 \\
75\end{array}$ & $\begin{array}{ll}18 \\
26\end{array}$ & $\begin{array}{l}-112 \\
-110\end{array}$ \\
\hline 6 & $\begin{array}{l}\alpha-\mathrm{D}-\mathrm{Glc} p- \\
-(1 \rightarrow 2)-\beta \text {-D-Fruf- } \\
-(1 \rightarrow 2)-\beta-\mathrm{D}-\mathrm{Fr} u f^{b}\end{array}$ & $\begin{array}{r}-98 \\
-110\end{array}$ & 33 & 92 & $\begin{array}{l}90 \\
79 \\
72\end{array}$ & $\begin{array}{ll}90 \\
82 \\
70\end{array}$ & $\begin{array}{l}a \\
a \\
a\end{array}$ & $\begin{array}{l}a \\
a\end{array}$ & $\begin{array}{l}a \\
a \\
a\end{array}$ \\
\hline 7 & $\begin{array}{l}\alpha-\mathrm{D}-\mathrm{Glcp} \\
-(1 \rightarrow-2)-\beta-\mathrm{D}-\text { Fruf } \\
-(3 \rightarrow 1)-\alpha-\mathrm{D}-\mathrm{Glc} p^{c}\end{array}$ & -112 & $\begin{array}{l}34 \\
41\end{array}$ & $\begin{array}{l}94 \\
90\end{array}$ & $\begin{array}{l}86 \\
89 \\
86\end{array}$ & $\begin{array}{l}90 \\
86 \\
86\end{array}$ & $\begin{array}{ll}25 \\
70 \\
22\end{array}$ & $\begin{array}{ll}1 & 8 \\
1 & 8 \\
2 & 0\end{array}$ & $\begin{array}{l}-112 \\
-118\end{array}$ \\
\hline
\end{tabular}

a Not detected ${ }^{b} J_{1} 1$ can be interchanged between both Fru $f$ residues $T$ The data for the series $J_{12}$ up to and including $J_{4} 5$ can be interchanged between both Glcp residues, independently of $J_{5} 6$, $J_{56}$, and $J_{66}$

Calculation of the dihedral angles between the ring protons from the observed coupling constants reveals that anomeric change does not affect the structure of the ring (Table III) The calculated dihedral angles for 1 and $\mathbf{2}$ do not differ significantly from the corresponding values in TMS-aldohexopyranoses ${ }^{1}$ (for 1,2-diaxial protons, 143 to $156^{\circ}$, for 1,2 -diequatorial or 1,2-axial-equatorial protons, 49 to $72^{\circ}$ ) Therefore, the deviations from the ideal chair conformation in 1 and 2 are of the same magnitude as in TMS-aldohexopyranoses

The structure of the D-glucopyranose residues in the oligosaccharides 5,6 , and 7 - The calculated dihedral angles between the ring protons of the Glc $p$ residues in the oligosaccharides 5,6 , and 7 and the mole fractions $(n)$ of the three most impor- 
TABLE III

CAICULATED DIHEDRAL ANGLES $\phi_{\mathrm{H}}$ FOR TMS- $\alpha$ - AND - $\beta$-D-FRU $p[(1)$ AND (2)]

\begin{tabular}{lllll}
\hline Compound & $\begin{array}{l}\phi_{34} \\
(\text { degrees })\end{array}$ & $\phi_{45}$ & $\phi_{56}$ & $\phi_{56}$ \\
\hline 1 TMS- $\alpha$-D-Frup & 153 & 53 & 50 & 64 \\
2 TMS- $\beta$-D-Frup & 158 & 53 & 62 & 70 \\
\hline
\end{tabular}

$\operatorname{tant}^{11} 12$ rotamers 1,2 , and 3 (F1g 3) of the $\mathrm{C}-5-\mathrm{CH}_{2}$ OTMS groups of these residues are given in Table IV The mole fractions are denved from the observed ${ }^{1}$ coupling constants $J_{5,6}$ and $J_{5,6}$. (Table $I$ ) For comparison, the data of TMS- $\alpha-D-G l c p$, which exists in the ${ }^{4} C_{1}$ (D) conformation, are included in Table $I V \quad \alpha-D$-Glcp retains this conformation when it forms part of the TMS-oligosaccharides 5 , 6, and 7 Table IV shows that the deformations of the pyranoid nings are similar to those in TMS- $\alpha-\mathrm{D}-\mathrm{Glc} p$. In all Glc $p$ residues, rotamer 3 of the $\mathrm{C}-5-\mathrm{CH}_{2}$ OTMS group is strongly preferred. This preference is greater in the oligosaccharides 5 and 7 than in TMS- $\alpha-\mathrm{D}-\mathrm{Gl} c p$, at the expense of rotamer 2 This conformational shift is probably due to the large Fruf residues at $\mathrm{C}-1$ in 5 and 7
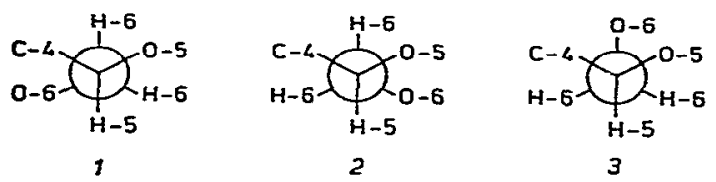

Fig 3 The three staggered rotamers 1,2 , and 3 of the $\mathrm{C}-5-\mathrm{CH}_{2}$ OTMS group in TMS-aldohexopyranoses and TMS-fructofuranoses

TABLE IV

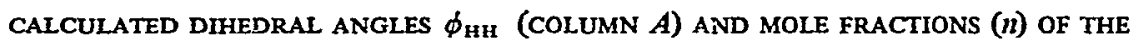
ROTAMERS 1,2 , AND 3 OF THE C-5-C-6 FRAGMENTS (COLUMN $B$ ) OF THE GLC $p$ MOIETIES IN SOME TMS-OLIGOSACCHARIDES AND OF TMS- $\alpha-D-G L C p$

\begin{tabular}{|c|c|c|c|c|c|c|c|}
\hline \multirow[t]{2}{*}{ Compound } & \multicolumn{4}{|l|}{$A$} & \multicolumn{3}{|l|}{$B$} \\
\hline & $\phi_{12}$ & $\phi_{23}$ & $\phi_{34}$ & $\phi_{45}$ & $\mathbf{n}_{\mathbf{1}}$ & $\mathbf{n}_{\mathbf{2}}$ & $\mathbf{n}_{3}$ \\
\hline TMS-sucrose (5) & 49 & 156 & 152 & 158 & 002 & 008 & 090 \\
\hline TMS-1-kestose (6) & 49 & 156 & 154 & 153 & & & a \\
\hline \multirow[t]{2}{*}{ TMS-meleztose (T) } & 48 & 158 & 151 & 153 & 002 & 008 & 090 \\
\hline & 42 & 154 & 151 & 151 & 004 & 006 & 090 \\
\hline TMS- $\alpha-D-G I c p^{b}$ & 50 & 154 & 151 & 156 & 000 & 023 & 077 \\
\hline
\end{tabular}

${ }^{a}$ Not determined $J_{56}$ and $J_{56}$ not observed ${ }^{b} \operatorname{Ref} 1$

The structure of the fructofuranose residues in 3-7 - For the determination of the structure of the Fruf rngs in compounds 3-7, the dihedral angles $\phi_{3,4}$ and $\phi_{4,5}$ 
(Table VA) were calculated from the observed coupling constants $J_{3,4}$ and $J_{4,5}$ (Table II) by using the modified Karplus relation The ideal dihedral angles $\phi_{3,4}$ and $\phi_{4,5}$ of the 20 possible twist $(T)$ and envelope $(E)$ conformations, with maximal puckerıng, were estımated from Dreiding molecular models (Table VI) Comparison of Tables VA and VI shows that, without additional information, the structure of the Fruf rings of $3-6$ cannot be described by a simple set of ideal conformations For TMS-melezitose (7), the magnitudes of $\phi_{3,4}$ and $\phi_{4,5}$, in combination with their difference $\left(\phi_{4} 5>\phi_{3} 4\right)$, point to the involvement of only the ${ }^{4} E(D)$ envelope and ${ }^{4} T_{5}$ (D) twist conformations This conclusion is supported by the consideration that,

\section{TABLE V}

CALCUI ATED DIHEDRAL ANGLES $\phi_{3}+$ AND $\phi_{4}$ S OF THE $\beta$-D-FRU $f$ RINGS OF THE TMS-SACCHARIDES (3-7) AND SOME PERACETYL ANALOGUES

\begin{tabular}{|c|c|c|c|c|c|}
\hline A & TMS deriuatıve & $\mathbf{J}_{\mathbf{3} 4}$ & $\mathbf{J}_{4,5}$ & $\phi_{34}$ & $\phi_{45}$ \\
\hline & $\begin{array}{l}\beta \text {-D-Fru } f(3) \\
\text { Me } \beta \text {-D-Fruf (4) } \\
\text { Sucrose (5) } \\
\text { 1-Kestose (6) ring A } \\
\text { Ming B } \\
\text { Melezitose (7) }\end{array}$ & $\begin{array}{l}55 \\
75 \\
81 \\
79 \\
72 \\
89\end{array}$ & $\begin{array}{l}55 \\
75 \\
81 \\
82 \\
70 \\
86\end{array}$ & $\begin{array}{l}135 \\
149 \\
154 \\
153 \\
147 \\
161\end{array}$ & $\begin{array}{l}139 \\
156 \\
162 \\
163 \\
151 \\
169\end{array}$ \\
\hline B & Acetyl derivative & & & & \\
\hline & $\begin{array}{ll}\text { Sucrose } & \\
\text { 1-Kestose } & \text { ring A } \\
& \text { ring B }\end{array}$ & $\begin{array}{l}55 \\
78 \\
60\end{array}$ & $\begin{array}{l}50 \\
69 \\
62\end{array}$ & $\begin{array}{l}136 \\
153 \\
140\end{array}$ & $\begin{array}{l}136 \\
151 \\
145\end{array}$ \\
\hline
\end{tabular}

${ }^{a}$ Coupling constants were obtained from $\operatorname{Ref} 8$

TABLE VI

DIHEDRAL ANGLES $\phi_{\text {H H }}$ FOR DIFFERENT IDEAL CONFORMATIONS ${ }^{\alpha}$ OF THE $\beta$-D-FRU $f$ RING WITH MIAXIMAL PUCKERING

\begin{tabular}{|c|c|c|c|c|c|}
\hline Conformation & $\phi_{34}$ & $\phi_{45}$ & Conformation & $\phi_{34}$ & $\phi_{45}$ \\
\hline${ }^{2} E$ & 150 & 120 & $E_{2}$ & 90 & 120 \\
\hline${ }^{2} T_{3}$ & 170 & 140 & ${ }^{3} T_{2}$ & 90 & 100 \\
\hline$E_{3}$ & 170 & 150 & ${ }^{3} E$ & 70 & 90 \\
\hline${ }^{4} T_{3}$ & 180 & 170 & ${ }^{3} T_{4}$ & 60 & 90 \\
\hline${ }^{4} E$ & 170 & 170 & $E_{4}$ & 70 & 70 \\
\hline${ }^{4} T_{5}$ & 170 & 180 & ${ }^{5} T_{4}$ & 90 & 60 \\
\hline$E_{5}$ & 150 & 170 & ${ }^{5} E$ & 90 & 70 \\
\hline${ }^{\circ} T_{5}$ & 140 & 170 & ${ }^{5} T_{0}$ & 100 & 90 \\
\hline${ }^{\circ} E$ & 120 & 150 & $E_{\mathrm{o}}$ & 120 & 90 \\
\hline${ }^{\circ} T_{2}$ & 100 & 140 & ${ }^{2} T_{0}$ & 140 & 100 \\
\hline
\end{tabular}

For nomenclature of conformations, see Ref 13 
in both conformations, the large substituents at C-3, C-4, and C-5 are onented equatorial or pseudo-equatorial ${ }^{7,8}$. Furthermore, the pseudo-axial orientation of the C-2-O-2 bond is favoured by the anomeric effect ${ }^{7,8}$

The calculated angles $\phi_{34}$ and $\phi_{45}$ of the Fruf rings in 5 and 6 are smaller than in 7; a further decrease of the angles is observed in 4 For each compound, $\phi_{45}$ is larger than $\phi_{34}$. It is reasonable to assume that the gradual decrease of the angles reflects a greater conformational freedom obtained by the successive replacement of a glycosyl residue by an OTMS group Consequently, for the structure of the furanoid rings in 4-6, in comparison to that of 7, contributions of conformations close to ${ }^{4} E(D)$ and ${ }^{4} T_{5}(D)$ have to be considered, as well as a decrease of the timeaveraged degree of puckering in the ${ }^{4} E(D)$ and ${ }^{4} T_{5}$ (D) conformations It seems unlikely that the substitution of a bulky OTMS group for a glycosyl residue will greatly facilitate the interconversion of conformations Hence, on the average, less puckering of the ring is more probable This assumption is in line with the calculated conformational preferences of the $\mathrm{C}-5-\mathrm{CH}_{2} \mathrm{OTMS}$ group of the Fruf residues Calculations of the mole fractions $n$ (Table VII) of the rotamers 1,2 , and 3 (Fig 3) of this group show that the amount of rotamer $l$ increases in the series $7,5,4$, and 3 This demonstrates a decreasing influence of the 1,3-parallel interaction between 4-OTMS and 6-OTMS The latter effect may arise from a less-equatorial position of 4-OTMS, indicating a dimınıshed, time-averaged puckerıng of the ring

\section{TABLE VII}

CALCULATED MOLE FRACTIONS ( $n$ ) OF THE ROTAMERS 1,2 , AND 3 OF THE C-5-C-6 FRAGMENT OF THE TMS-FRUCTOSE DERIVATIVES 3 AND 4 AND THE $\beta$-D-FRU $f$ RESIDUES IN 5 AND 7

\begin{tabular}{llll}
\hline TMS-derivative & $\mathrm{n}_{1}$ & $\mathrm{n}_{2}$ & $\mathrm{n}_{3}$ \\
\hline$\beta$-D-Fruf $(3)$ & 025 & 037 & 038 \\
Me $\beta$-D-Fruf (4) & 016 & 029 & 055 \\
Sucrose (5) & 008 & 062 & 030 \\
Melezitose (7) & 000 & 057 & 043 \\
\hline
\end{tabular}

The Fruf rings of TMS-1-kestose (6) can be identified as follows The terminal Fruf residue in 1-kestose is attached to the other Fruf $\imath$ ia a methylene bridge and therefore resembles methyl $B$-D-fructofuranoside The angles $\phi_{3,4}$ and $\phi_{4,5}$ of ring B agree indeed with those of methyl TMS- $\beta$-D-fructofuranoside (4) Hence, ring $B$ is assigned to the terminal Fruf and ring $\mathrm{A}$ is the Fruf attached to D-glucose The angles of ring $A$ are equal to those in TMS-sucrose (5), and so its structure is not influenced by the terminal Fruf.

The values of $\phi_{3,4}$ and $\phi_{4,5}$ observed for TMS- $\beta$-D-Fruf (3) deviate strongly from those found for the methyl glycoside 4. The replacement of an OMe group at C-2 by an OTMS group has a profound influence on the structure of the ring The most probable explanation is that the greater cquatorial directing effect of the OTMS group results in a flattening of the ring 
From literature data ${ }^{8}$, the dihedral angles of the Fru $f$ rings in the peracetates of sucrose and 1-kestose were calculated (Table VB) In all cases, $\phi_{3,4}$ is nearly equal to $\phi_{45}$, indicating that, in contrast to the TMS-derivatives, the ${ }^{4} E$ (D) conformation is favoured ( $c f$. refs 7 and 8) However, the angles in the acetyl derivatives are smaller than in the corresponding TMS-dernvatives, reflecting a greater conformational freedom This is in agreement with the observation ${ }^{1}$ that OTMS groups hinder each other more than OAc groups

\section{DISCUSSION}

TMS-derivatives of oligosaccharides containing D-glucose and D-fructose are suitable for conformational analysis by $\mathrm{p} \mathrm{m} \mathrm{r}$ spectroscopy, because the spectral parameters that give structural information can easily be obtained The characteristic patterns of $\mathrm{H}-3$ and $\mathrm{H}-4$ of the Fruf rings are well separated from the signals of the remaining non-anomeric protons and the same holds for $\mathrm{H}-1$ and $\mathrm{H}-2$ (and sometımes for $\mathrm{H}-4$ ) of the Glcp residues Consequently, the corresponding coupling constants can be determined accurately In per- $O$-acetyl derivatives ${ }^{8}$, these protons resonate within the range of the remaining protons, which hampers the elucidation of the structure

For the interpretation of coupling constants in terms of conformation(s) of the Fruf ring, as reported in the literature ${ }^{78}$, additional stereochemical evidence is indispensable However, the structure of the Fruf ring in TMS-melezitose (7) could be derived unambiguously from the coupling constants only This permitted the use of stereochemical factors, like the anomeric effect and the interactions between substituents, as independent data to derive the structure of the Fruf ring in compounds related to TMS-melezitose (7) Starting from the coupling constants of 7 , a systematic decrease of $J_{3,4}$ and $J_{4,5}$ is observed when glycosyl groups are replaced by OTMS groups or OTMS groups by OAc groups This finding led to the conclusion that the Fruf rings in these compounds have the same basic structure and that the freedom to adopt neighbouring forms is greater when smaller substituents are attached to the ring The decrease in rigidity of the ring can be conceived as a rapid interconversion of envelope and twist conformations close to the ${ }^{4} E(D)$ and ${ }^{4} T_{5}(D)$ and/or an increase of the participation of less-puckered forms of the ${ }^{4} E(D)$ and ${ }^{4} T_{5}(D)$ conformations The calculated, conformational preferences of the C-5 substituents favour the last possibility

EXPERIMENTAL

D-Fructose, raffinose, melezitose, and sucrose were obtained commercially. 1-Kestose was supplied by Professor W Kahl Methyl $\beta$-D-fructofuranoside was synthesized according to Horvath et al ${ }^{14}$.

G I c was performed on an F and M Gas Chromatograph Model 700, equipped with a dual flame-1onization detector and colled stainless-steel columns $(270 \mathrm{~m} \times$ 
$32 \mathrm{~mm}$ ) contaning $3 \%$ OV-17 on Chromosorb W(HP), 80-100 mesh, at $150^{\circ}$ for monosacchandes, at $228^{\circ}$ for the disaccharide, and at $270^{\circ}$ for trisaccharides, nitrogen was used as carrier gas

Per-O-trimethylsilyl derivatives. - For the preparation of compounds 1-3, D-fructose was anomerized in dry pyridine at $80^{\circ}$ for $2 \mathrm{~h}$ and subsequently treated ${ }^{3}$ at $80^{\circ}$ with hexamethyldisilazane and chlorotrimethylsilane The separation of the anomers was achieved by preparative $t \mathrm{l} c$, using Silica Gel G (Merck) and dry benzene ${ }^{15}$. After spraying with $1 \%$ monne in methanol, the zones were detected under u v. light and extracted with chloroform For the identification of these compounds, use was made of $\mathrm{g} 1 \mathrm{c}-\mathrm{m} \mathrm{s}^{10}$ Compounds $4-7$ were obtaned directly by silylation of the corresponding free saccharides, their purity was tested by $\mathrm{g} l \mathrm{c}$

$P m$ r. spectroscopy. - This was performed on a Varian HR-220 spectrometer (TNO Central Laboratories, Delft, The Netherlands) or a Varian HA-300 spectrometer (Laboratory of N.m r spectroscopy, Ghent, Belgium) at a probe temperature of $\sim 25^{\circ}$ Spectra of the pure TMS-denvatives were recorded for 2-6\% (monosacchandes), $6 \%$ (disacchande), or $15 \%\left(\mathrm{w} / \mathrm{v}\right.$ ) (trisacchandes) solutions in acetone- $d_{6}$ Spectrum simulations were run on a $16 \mathrm{k}$ Varian $620_{1}$ computer coupled with a Varian XL-100 FT spectrometer, using a modified and extended SIMEQ ${ }^{9}$ spinsimulation programme Chemical shifts are given relative to tetramethylsilane (indirect to acetone- $d_{6} \delta 205 \mathrm{p} \mathrm{p} \mathrm{m}$ ) with an accuracy of $\sim 0005 \mathrm{p} \mathrm{p} \mathrm{m}$ The accuracy of the coupling constants is $\sim 01 \mathrm{~Hz}$

\section{ACKNOWLEDGMENTS}

We thank Professor W Kahl (Krakow, Poland) for the gift of 1-kestose, Ir. P E J Verwel and Mr J L Hoogendoorn (TNO Central Laboratories, Delft, The Netherlands) for recording the 220-MHz spectra, Professor $M$ Anteunis and Dr G J Gelan (Laboratory of N $\mathrm{m} r$ spectroscopy, Unıversity of Ghent, Belgium) for recording the 300-MHz spectra, and Dr J. Vink (Laboratory of Analytical Chemistry, Utrecht, The Netherlands) for recording the 70-eV mass spectra This investigation was supported by the Netherlands Foundation for Chemical Research (SON) with financial ald from the Netherlands Organization for the Advancement of Pure Research (ZWO)

\section{REFERENCES}

1 D G Streefkerk, M J A De Bie, ANd J F G Vliegenthart, Tetrahedron, 29 (1973) 833

2 D. $G$ STREEFKerK, $M$ J A DE BIE, AND J F G VIIEgenthart, to be published

3 J P Kamerling, M I A De BIE, and J F G Vliegenthart, Tetrahedron, 28 (1972) 3037

4 P L Durette and D Horton, Advan Carbohyd Chem Blochem, 26 (1971) 111

5 J. D. Stevens and H G Fletcher, JR, $J$ Org Chem, 33 (1968) 1799

6 L D Hall, P R Steiner, ANd C Pedersen, Can $J$ Chem, 48 (1970) 1155

7 R U LemieuX and R Nagarajan, Can $J$ Chem, 42 (1964) 1270

8 W W Binkley, D Horton, and N S Bhacca, Carbohyd Res, 10 (1969) 245

9 C W. F. KORT AND P J YAN DER HAAK, University of Amsterdam, personal communication $10 \mathrm{~J}$ Ravanaugh and B P Danlex, $J$ Chem Phys, 34 (1961) 1099. 
11 R. U Lemieux and J D Stevens, Can $J$ Chem, 43 (1965) 2059

12 D Horton and M J Miller, $J$ Org Chem, 30 (1965) 2457

13 J F. Stoddart, Stereochemistry of Carbohydrates, Wiley-Interscience, New York, 1971, 97

14 A. E HoRvath AND R L Metzenderg, Blochim Blophys Acta, 74 (1963) 165

15 J LeHRFELD, J. Chromatogr, 32 (1968) 685

16 H -Ch Curtrus, M Muller, AND J A Volzain, J Chromatogr, 37 (1968) 216 